\title{
Como o distanciamento social em tempos de pandemia desafia os estágios iniciais da aprendizagem da leitura em crianças
}

How social detachment in times of pandemic challenges the early stages of learning to read in children

\author{
Letícia Priscila Pacheco
}

Instituto Federal Sul - IFSul - Rio Grande do Sul - Brasil

\section{Lilian Cristiane Hübner ${ }^{(1)}$}

Pontifica Universidade Católica - PUCRS - Rio Grande do Sul - Brasil

\begin{abstract}
Resumo: Este artigo tem por objetivo discutir o distanciamento social em tempos de pandemia do COVID-19 no desenvolvimento inicial da I em crianças. Mais especificamente, discutiremos os processos envolvidos na aprendizagem da leitura, os transtornos mais comuns relacionados ensino não-presencial. Discutiremos o cenário que se apresenta e como ele impacta nas questões relacionadas ao período inicial de ensino e aprendizagem da leitura. Em tempos de pandemia e distanciamento social, é necessária uma ação conjunta, contínua e eficiente entre professores, pais e governos, visto que a orientação da criança para a construção da consciência da relação grafemafonema e a criação de um espaço privilegiado para a I são condições essenciais para o desenvolvimento
\end{abstract}

Palavras-chave: aprendizagem da leitura, dificuldades de leitura, pandemia.

\begin{abstract}
This paper aims at discussing the social distancing during the COVID-19 pandemic to the initial phases of development in children. More specifically, we will discuss the processes involved in learning to read, the most common difficulties. We will discuss the scenario at pandemic and how it impacts in the issues related to the initial phase of teaching and learning to read In times of pandemic and social distancing, a conjunct, continuous and efficient action between teachers, parents and governments is essential, since the child's awareness raising for the construction of the graphemephoneme relationship, and the creation of a privileged space for literacy are essential conditions for its development.
\end{abstract}

Keywords: learning, difficulties, pandemic. 


\section{Introdução}

São grandes os desafios da educação no Brasil e esta constatação é verdadeira há muito tempo. Há um abismo de diferenças entre as mais diversas realidades educacionais, entre os mais variados públicos atendidos. Junto a isso, devido à grandiosidade territorial do país, são evidentes as diferenças culturais, sociais e econômicas. A estrutura educacional brasileira é muito diversa e ainda engatinha rumo ao acesso pela maior parte da população, quiçá toda ela, à educação de qualidade, o mesmo ocorrendo em relação ao acesso a um sistema ágil e eficiente de saúde, à estrutura básica de saneamento e a uma alimentação adequada.

Neste texto propomos uma discussão a respeito dos desafios impostos pelo distanciamento social decorrente da Covid-19 no processo de aprendizagem da leitura por crianças em idade escolar, em classes de alfabetização. Para tanto, abordamos algumas das dificuldades que se apresentam no contexto ensinoaprendizagem remoto, incluindo o caso de crianças com dificuldades ou transtornos na aprendizagem da leitura, em busca de uma relação entre o distanciamento social, o novo modelo de ensino remoto de caráter emergencial e as dificuldades a serem superadas pelas crianças que iniciam 0 processo de aprendizagem da leitura e seus professores. O tema da leitura já é amplamente discutido no país, visto que os índices não têm sido muito promissores ao longo dos anos. Desse modo, um contexto de pandemia impõe mais um desafio a esse quadro que já demandava atenção por parte das escolas e do governo.

De acordo com o Instituto Brasileiro de Geografia e Estatística (IBGE) (2020), a partir da Pesquisa Nacional de Amostra por domicílios, em 2009 a taxa de analfabetismo funcional do Brasil ficou em 20,3, sendo que a média de anos de estudo de pessoas com 10 anos ou mais de idade era de 7,2 anos. $O$ analfabetismo e a baixa escolaridade seguem repercutindo atualmente, nos baixos índices de acerto em tarefas de leitura. Por exemplo, em 2018 os resultados do PISA (OECD, 2018) relacionados à leitura indicaram que os estudantes brasileiros tiveram resultados inferiores à média. Segundo os dados, 50\% dos estudantes alcançaram ao menos o nível 2 de proficiência em leitura, o que demonstra que estes estudantes são capazes de identificar as ideias principais em textos de comprimento moderado, identificar informações com base em critérios explícitos, também em alguns critérios complexos e refletir sobre o propósito e formato destes textos. Apenas $2 \%$ dos estudantes atingiram os níveis 5 e 6 da avaliação, os quais indicam a capacidade de ler textos complexos, tratar de contextos abstratos e estabelecer distinção entre fatos e opiniões, dentre outras habilidades.

Muitas iniciativas de apoio ao ensino básico têm ocorrido nos últimos anos em nível nacional. No entanto, os baixos índices que alcançamos nos indicadores internacionais mostram o quanto ainda precisamos evoluir para atingirmos níveis de leitura, num sentido amplo de literacia, que sejam suficientes para que a população consiga compreender todo o tipo de informação que faz parte de suas vidas diárias. Mas, como se define literacia? Segundo Morais (2019, p. 9-10), a literacia pode ser entendida em três sentidos, sendo eles: 1) a habilidade de ler e escrever de forma hábil, 2) a capacidade de usar esta habilidade para adquirir, criar e transmitir conhecimentos e desenvolver a própria linguagem assim como capacidades cognitivas (como memória, percepção, atenção) para prazer pessoal e engajamento social e 3) a sua manifestação em domínios da literacia (isto é, em determinada área, como a comunicação, informática, da saúde, financeira). Teixeira e Townsend (2020, p. 2) mencionam que Kolinsky, em sua fala no evento Abralin ao Vivo, define o termo como sendo a utilização eficiente e frequente da leitura e da escrita. Dentro desta concepção, mais do que saber ler, é preciso saber compreender, construir sentidos. Neste artigo, elegemos e delimitamos mais especificamente questões atinentes à aprendizagem da leitura, devido à colocação do nosso país nos rankings nacionais e internacionais de avaliação da compreensão leitora e às incertezas e aos desafios impostos pela pandemia. Outrossim, a leitura constitui 
uma porta de entrada para a informação, instigando questionamentos e, dessa forma, ampliando os horizontes do conhecimento. A importância da leitura no nível social é imensa e complexa. Quando nos perguntamos por que tantas notícias falsas e informações manipuladas ganham tamanha repercussão estamos constatando o quanto a falta de habilidades consolidadas para a compreensão do que é lido surte consequências, por exemplo, nos movimentos sociais.

Abrindo 0 leque dos efeitos do desenvolvimento da leitura, destacamos o impacto do desenvolvimento desta habilidade na cognição humana. Segundo Dehaene (2012, p. 255), a leitura "esperta" depende de uma feliz combinação de conexões que temos a chance de possuir, começando a se estabelecer desde o início em nosso cérebro infantil, e reciclados a partir dos anos de aprendizagem escolar em virtude de um novo uso - a leitura e a escrita. Diversos estudos demonstram que há um impacto positivo na ativação neuronal e na implementação de processos cognitivos mais complexos e efetivos a partir do momento em que aprendemos a ler e a escrever. Abre-se, assim, uma nova realidade diante dos olhos de quem lê. Morais (2013, p. 11) propõe que ler implica um sistema mental de tratamento da informação escrita, isto é, um conjunto complexo de operações de transformação de representações em outras representações. As letras, antes vistas como imagens em sequência, sem sentido específico atribuído, passam a ser percebidas e diferenciadas em seus traços mais sutis. Cosenza e Guerra (2011, p. 101) explicam que a aprendizagem da leitura modifica permanentemente o cérebro, fazendo com que ele reaja de forma diferente não só aos estímulos linguísticos visuais, mas também na forma como processa a própria linguagem falada. Ainda no sentido de esclarecer como ocorrem as condições necessárias para a construção dos conhecimentos, Rotta (2016, p. 469) lembra que as funções corticais envolvidas na cognição são expressões da plasticidade cerebral e acrescenta que a aprendizagem é definida como modificações do sistema nervoso central (SNC), mais ou menos permanentes, quando o indivíduo é submetido a estímulos e/ou experiências de vida, que serão traduzidas em modificações cerebrais.

Cabe aqui ressaltar, no entanto, que o processo de leitura não se inicia nos bancos escolares. No meio familiar, a criança começa seu processo de exposição aos usos da escrita. Experiências de leitura compartilhada, contação de histórias, contato físico com livros e o exemplo de pais e familiares leitores podem servir como motivação inicial para que a criança tenha ainda maior interesse na aprendizagem da leitura. Assim sendo, verifica-se a diferença entre crianças expostas a maior quantidade e qualidade de input linguístico, em forma impressa ou digital, na comparação com crianças menos privilegiadas neste sentido. Neste último caso, a exposição e exploração de material de leitura e de escrita na educação infantil e/ou nos anos escolares iniciais torna-se ainda mais crucial, pois para muitas crianças pode ser o primeiro contato com este tipo de material. Este fato causa preocupação quanto às consequências da privação deste contato na escola por causa do isolamento social demandado pela Covid-19.

A pandemia da Covid-19 tornou ainda mais evidentes as discrepâncias entre as diferentes realidades vividas pelos pequenos estudantes. Ao mesmo tempo em que crianças que frequentam escolas da rede privada têm acesso a aulas virtuais com as ferramentas digitais mais avançadas e professores capacitados para a prática, crianças das redes públicas foram introduzidas a um ensino remoto de caráter emergencial, muitas vezes sem contar com as condições básicas de acesso às aulas e/ou de acompanhá-las. Muitos estudantes, ao receberem o link de acesso às aulas, não possuíam equipamentos eletrônicos para acessar o material disponibilizado e se engajar nas atividades remotas. Ou ainda, recebiam as atividades impressas, mas pais ou cuidadores analfabetos ou semianalfabetos não tinham condições de oferecer auxílio para filhos nas séries iniciais entenderem a proposta da atividade encaminhada. As aulas passaram a ser conduzidas por professores que, na maioria dos casos, não utilizavam ferramentas 
digitais no cotidiano da sala de aula, ou não haviam recebido treinamento para o seu uso.

Apesar das dificuldades impostas, em especial às crianças menos favorecidas no cenário do ensino remoto, a aprendizagem não pode parar, e o desenvolvimento cognitivo, social, motor da criança precisa de estímulo constante. As etapas do desenvolvimento infantil são muito sensíveis e a qualidade e quantidade do estímulo poderá definir o tamanho do sucesso ou do fracasso escolar e profissional que ela obterá.

No entanto, é preciso discutir o quanto deste desenvolvimento é confiado às instituições escolares como únicos ou principais responsáveis por sua efetivação. A criança vive, pensa, vê, explora, a cada segundo de sua existência. Muitos dos questionamentos mais significativos ocorrem durante a brincadeira, durante a interação entre os pares tanto no ambiente escolar quanto no familiar, em todas as circunstâncias. Quando privadas do ambiente escolar presencial, como ocorre no atual momento de pandemia, muitas crianças não recebem estímulos adequados ou suficientes, debilitando 0 desenvolvimento propiciado pela interação, pelo convívio com outras crianças e com os profissionais da educação. Isso reforça a necessidade de os pais, neste momento, tentarem compensar e amenizar dentro do possível a redução do contato com os colegas e professores, ao exporem as crianças a jogos didáticos, material de leitura usando-o de forma interativa, além de acompanharem a execução de tarefas escolares. Especificamente em relação à leitura, o início do seu processo de aprendizagem ocorre com a introdução da criança ao mundo letrado, exposta aos hábitos familiares e escolares de exploração de livros e revistas ou material de leitura digital, o acesso e a compreensão progressiva de que as letras podem se constituir como palavras cheias de significado e representações do mundo. A partir do momento em que a construção da palavra escrita e os sons que as compõem passam a povoar o pensamento da criança, um novo modo de olhar o mundo é descoberto, e este olhar irá permear as construções mentais dali para a frente. Assim, destaca-se o papel da família no desenvolvimento da habilidade de leitura e da literacia infantil, que se reforça ainda mais em contexto de pandemia.

Apesar de a família ser responsável legal pelo zelo com a criança e por garantir seu desenvolvimento, a escola tem papel primordial na oferta de oportunidades de crescimento social, cognitivo, intelectual e motor. Para além da necessidade da participação ativa do ambiente familiar, existem habilidades e etapas do desenvolvimento fortemente dependentes de instrução e de acompanhamento adequados pela escola. Fonseca (2011, p. 70) sugere que a capacidade de pensar ou de raciocinar não é inata e que as funções cognitivas não se desenvolvem se não forem objeto de treino sistemático e de mediação contínua pelo professor. O desenvolvimento da leitura e a construção da consciência fonológica são habilidades que podem ser destacadas dentro deste contexto (NUNES; BUARQUE; BRYANT, 1992; DEHAENE, 2009; COSENZA; GUERRA, 2011; MORAIS, 1996, 2019). Neste sentido, torna-se uma preocupação o fato de muitas crianças não estarem recebendo neste momento a atenção necessária para este desenvolvimento e as consequências poderão ser sentidas e avaliadas num futuro próximo. Na próxima seção, abordaremos questões atinentes à aprendizagem e ao processamento da leitura, para em seguida enfocar situações em que problemas impactam esta aprendizagem e, finalmente, discutir os desafios advindos da pandemia na questão do ensino e da aprendizagem inicial da leitura.

\section{Aprendizagem e processamento da leitura}

Os processos envolvidos no desenvolvimento da leitura acionam capacidades sensoriais e cognitivas que coparticipam de modo complexo. Dentre tantas formas de se observar e entender a aprendizagem e o desenvolvimento da leitura, assume-se a ideia de que podemos aprender a processar as palavras a partir de nosso conhecimento prévio e, nesse sentido, poderemos aos poucos criar e realimentar uma memória proveniente de nossas experiências com o mundo na dimensão das palavras. Mais 
especificamente, o arcabouço de conhecimentos que irá conduzir o ritmo do desenvolvimento das funções de linguagem e demais aspectos cognitivos é construído desde o momento do nascimento, quando a criança passa a ter acesso a uma grande variedade de estímulos. Sob esta perspectiva, Lent (2018, p. 13) explica que aprendizagem envolve um indivíduo com seu cérebro, captando informações do ambiente, guardando-as por algum tempo e, eventualmente, utilizando-as para orientar seu comportamento subsequente. Cada vivência, cada estímulo sensorial, cada interação com seus pares passa a constituir as memórias, as representações da criança, o que será necessário para que esta se desenvolva e construa sua linguagem e demais habilidades cognitivas.

Cosenza e Guerra (2011, p. 104) argumentam que o aprendiz de leitura utiliza o sistema fonológico para decodificar palavras novas ou irregulares e que, com o aumento da habilidade, o cérebro torna-se capaz de reconhecer os padrões ortográficos de maneira a processá-los rapidamente e automaticamente. Esta perspectiva tem base no chamado modelo de dupla via, ou modelo de dupla rota (COLTHEART, 2005). De acordo com o autor, a diferença entre os processos de leitura de palavras já conhecidas e de palavras novas é que palavras novas são lidas pela via fonológica, a partir da decodificação grafo-fonológica, transformando grafemas em fonemas (rota não-lexical), enquanto as palavras já conhecidas seriam lidas por um processo de identificação direta, de forma que seria possível a decodificação semântica mais rapidamente (rota lexical). Segundo Coltheart (2005, p. 9),

a leitura via rota lexical envolve consultar a palavra no léxico mental contido no conhecimento sobre a escrita e pronúncia de sequências de letras que são palavras verdadeiras (e estão presentes no léxico); a leitura via rota não-lexical faz a referência a este léxico, porém envolve o uso de regras para relacionar segmentos ortográficos a segmentos fonológicos.

A evolução no processamento da leitura seguiria, assim, o fluxo das experiências do leitor. À medida que o léxico mental recebe maior volume de input, o leitor tem mais subsídios para acessar a palavra em seu todo e de forma mais automática.

Coltheart (2005) também argumenta que algumas dificuldades na aprendizagem da leitura poderiam ser explicadas por meio desta teoria, ilustrando com o fato de que, nos diferentes padrões de dislexia conhecidos, o uso tanto de uma quanto de outra rota pode ser observado, com padrões diferentes dos usados por leitores hábeis (rota fonológica para palavras desconhecidas ou pseudopalavras e rota lexical para palavras cuja leitura encontra-se automatizada).

Finalmente, é importante ressaltar que, diferentemente da aquisição da fala, para a qual bastam a exposição e capacidades cognitivas e físicas adequadas, a habilidade de leitura precisa ser ensinada. É necessário um esforço consciente por parte do aprendiz, seja em qual for a idade de aquisição, bem como a mediação de um professor ou tutor. No entanto, há casos em que ocorrem limitações individuais relacionadas a processos neurológicos, psicológicos e sociais que dificultam a aprendizagem da leitura (e por consequência de outros domínios escolares) e que na maior parte dos casos passam a ser identificados apenas ao longo do período de aprendizagem da leitura no âmbito escolar. A próxima seção trata de alguns exemplos de dificuldades e de transtornos da leitura.

\subsection{Dificuldades e transtornos da} aprendizagem e do processamento da leitura

Ao iniciarmos a discussão, é importante estabelecer-se uma distinção entre dificuldades de leitura e transtornos de leitura. Há uma enorme diversidade de questões que podem vir a interferir no processo de desenvolvimento da leitura pela criança. Algumas vezes as dificuldades surgem por causa de deficiências ligadas aos estímulos sensoriais, como a visão reduzida, audição limitada, além de defasagem cognitiva nos mais diversos graus. Quando o empecilho para o desenvolvimento da leitura pode ser superado por treino, estimulação e atendimento especializado, este é chamado de dificuldade de 
aprendizagem da leitura; já quando a origem deste impedimento faz com que as limitações do leitor se mantenham, ainda que com algum grau de desenvolvimento, denominamos transtorno de aprendizagem de leitura, como é o caso de alguns disléxicos (LEAL; NOGUEIRA, 2012). Por exemplo, Cosenza e Guerra (2011) esclarecem que, de modo geral, crianças com dificuldades na leitura podem vir a superá-las com ajuda adequada; porém há crianças que apresentam dislexia do desenvolvimento e mantêm esse prejuízo, mesmo empenhando muito esforço e dedicação.

Aprendizes podem apresentar dificuldades de leitura nos mais diversos aspectos. Se pensarmos que, ao ler, ativamos todo um sistema que irá trabalhar para que o objetivo comum da decodificação e da construção do sentido seja atingido, entendemos a complexidade dos processos envolvidos na leitura e consequentemente, na sua aprendizagem. Relvas (2015, p. 45) aponta que as dificuldades de aprendizagem não estão ligadas apenas aos sistemas biológicos cerebrais, mas podem também ser causadas por problemas passageiros de ordem, por exemplo, sensorial ou afetiva. No que diz respeito à suscetibilidade dos aprendizes às interferências externas, sabemos que

A definição das dificuldades para a aprendizagem passa, em primeiro lugar, pelo conceito de aprendizagem. Não há dúvida de que o ato de aprender está sediado no SNC, onde ocorrem modificações funcionais e condutuais que dependem do contingente genético de cada indivíduo, associado ao ambiente onde esse ser está inserido. O ambiente é responsável pelo aporte sensitivo-sensorial, que é adquirido por meio da substância reticular ativadora ascendente e é modificado pelo sistema límbico, que contribui com os aspectos afetivo-emocionais da aprendizagem. (ROTTA, 2016, p. 97)

Algumas vezes as limitações de aprendizagem da leitura são expressivas e implicam a necessidade de estímulos mais incisivos, atendimento educacional especializado, ou até, em casos extremos, medicação para inibição, controle ou estimulação de processos mentais. Por isso, é interessante que o educador busque conhecimentos básicos sobre o funcionamento normal e patológico do sistema nervoso central e sua relação com o processo de aprendizado da criança (RIESGO, 2016, p. 9), a fim de compreender a sequência em que ocorrem os eventos neuromaturacionais da criança enquanto ela cresce, se desenvolve e também aprende (RIESGO, 2016).

Mesmo quando não muito aparentes, as dificuldades no desenvolvimento da leitura podem promover defasagens em diferentes habilidades a serem desenvolvidas e, desta forma, refletir na qualidade do desenvolvimento da criança ou do jovem. Isso ocorre porque a leitura e a escrita são as formas mais comuns de acessar e adquirir conhecimento em sala de aula, já entre as crianças nos anos iniciais de escolarização. O desafio da educação, neste contexto, é promover e incentivar a busca pelo conhecimento de formas diferenciadas, oportunizando aos estudantes que, por um motivo ou outro, não obtenham sucesso em suas tarefas escolares pelos meios mais comuns utilizados pelos educadores, recebam outras formas de instrução, até que desenvolvam de algum modo e em alguma extensão suas habilidades cognitivas. Sobre este papel da educação, lemos que:

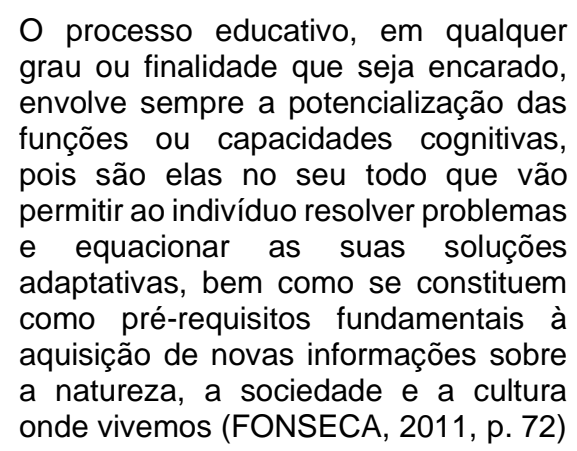

Dada a sua origem, as dificuldades ou os transtornos da leitura nem sempre são resolvidos por completo. No entanto, o esforço da família, professores e profissionais especializados é imprescindível para que a criança ou o jovem desenvolva sua literacia em alguma extensão e profundidade. Sabemos hoje que, assim como as demais dificuldades de aprendizagem, os obstáculos relacionados à leitura têm origens e sintomas diversos. Segundo o modelo de via única de leitura, acreditava-se inicialmente que dificuldades com a decodificação apresentadas por crianças na fase de pré-leitura eram ocasionadas por prejuízo no processamento fonológico. Estas, por sua vez, causariam dificuldades na compreensão posterior 
"porque palavras individuais devem ser decodificadas antes que as frases e o texto mais longo possam ser entendidos" (VAN KLEECK; NORLANDER, 2008, p. 279)

No entanto, tomando como base a compreensão da leitura pelas vias lexical e não-lexical, dadas as características de ambas as vias, emergem peculiaridades a serem observadas. Van Kleeck e Norlander (2008) explicam que, em geral, crianças com dificuldades no nível fonológico enfrentam maiores obstáculos para reconhecer e decodificar palavras escritas ou impressas, enquanto crianças com transtornos não fonológicas conseguem decodificar a escrita, porém mais tarde tendem a apresentar problemas na compreensão textual. Consequentemente, as crianças que apresentam dificuldades nos níveis fonológicos e não fonológicos irão apresentar complicações na decodificação de palavras assim como no nível textual.

Ferreira (2014) denomina as diferentes dislexias e dificuldades de aprendizagem de leitura segundo sua origem e características. Assim, a autora agrupa os disléxicos em: disléxicos fonológicos (não conseguem realizar a decodificação fonológica, apresentam muitas dificuldades na leitura de palavras não familiares e pseudo-palavras, assim com apresentam limitações acentuadas na memória de curto prazo fonológica e, consequentemente, no desenvolvimento da consciência fonológica); disléxicos de superfície (não conseguem usar a rota lexical, apresentando dificuldades de processamento da informação e leitura de palavras irregulares); disléxicos mistos (demonstram dificuldades tanto no nível fonológico quanto no nível lexical) e os leitores atrasados (apresentam padrão de leitura semelhante ao dos leitores normais, porém equivalente ao de leitores mais jovens). Sobre o caso deste último grupo, podemos considerar ainda as limitações referentes ao ensino, no que tange à qualidade e à quantidade em que este é oferecido à criança e ao jovem. É claro que leitores atrasados podem ter lacunas advindas de questões individuais, como déficit de atenção ou na capacidade de memória de trabalho (BUITELAAR; VAN DER MEER; RICHARDS, 2019), ou ainda advindas de questões relacionadas ao âmbito familiar ou social, quando estes, por exemplo, não estimulam a literacia (SOUSA; HÜBNER, 2017). Entretanto, os leitores atrasados podem, muitas vezes, representar um retrato da ineficiência da escola, que em muitas situações, dá conta de ensinar apenas àqueles estudantes que já demonstram facilidade na aprendizagem e se encontram altamente motivados a aprender

Além das dificuldades de aprendizagem de leitura, acima discutidas, há os casos de transtornos de aprendizagem, como é o caso da dislexia. Alguns autores (FONSECA, 2011; FERREIRA, 2014; ALTREIDER, 2016) alertam para os sinais mais expressivos da presença de dislexia. Segundo eles a identificação das letras do alfabeto, percepção na distinção dos sons, dificuldades de memorização no início das tarefas formais de aprendizagem são os sinais mais precoces. Dehaene (2012, p. 258) acrescenta que as crianças disléxicas parecem sofrer acima de tudo de uma representação imperfeita das palavras faladas, o que atrapalha seu emparelhamento com os signos escritos. Altreider (2016, p. 232) alerta que, como cada um dos processos de aprendizagem de escrita envolve diferentes aquisições psicomotoras e cinestésicas, é no mínimo prudente privilegiar somente um dos modelos de escrita (letra bastão, de imprensa ou cursiva) quando existe a possibilidade de se ter um aluno com sinais de dislexia. Outra alternativa seria o apoio de um profissional capacitado para o atendimento especializado na escola, visando à consolidação do desenvolvimento da leitura através do modelo de escrita adotado e ainda o aumento na estimulação para a solidificação dos processos subjacentes à leitura, como a memorização de sons, grafia de letras e palavras mais frequentes, exercícios reflexivos de leitura oralizada para que o estudante tenha a oportunidade de ouvir a si mesmo e aos outros durante as situações de decodificação das palavras. É possível utilizar as ferramentas digitais disponíveis e enriquecer o material oferecido aos estudantes, de modo que, ao beneficiarem-se das tecnologias atuais, estes desenvolvam suas habilidades cognitivas de forma contínua e integrada ao seu nível de 
desenvolvimento. As atividades podem ser incrementadas com o uso de jogos lúdicos no computador, em que as crianças podem, em casa ou na escola, praticar mais a relação entre fonemas e grafemas, figuras e palavras relacionadas pelo sentido, de modo a aumentarem a quantidade e a qualidade da estimulação para a leitura. De acordo com Dehaene (2012), novas estratégias de reeducação baseadas na aprendizagem intensiva no computador melhoram os escores de leitura e conduzem a uma normalização parcial da atividade cerebral das crianças disléxicas.

De acordo com Ferreira (2014, p. 216), os problemas de leitura tendem a ser a principal dificuldade nos primeiros anos da escola, mas mesmo muitos disléxicos tornam-se leitores fluentes, ainda que com ortografia deficiente.

Independentemente das ações adotadas para dar subsídios aos estudantes que necessitam de maior atenção educacional para o desenvolvimento das habilidades de leitura, é salutar atentar para que o educador e a família trabalhem em conjunto a fim de buscar formas de estimular os estudantes. Outrossim, o trabalho multidisciplinar tende a ser um andaime importante para que crianças e adolescentes que sofrem por não atingir os objetivos de desenvolvimento cognitivo e linguístico referentes à competência leitora possam evoluir e alcançar um patamar um pouco mais elevado no desenvolvimento de suas competências. Desse modo, o trabalho conjunto entre pais, professores, equipe pedagógica e assistência fonoaudiológica, se disponível, provê suporte para a superação de possíveis dificuldades.

Como vimos anteriormente, nem sempre é possível uma solução para os transtornos de aprendizagem, porém todos têm direito ao acesso ao atendimento educacional especializado. A lei no 9.394, de 20 de dezembro de 1996, em seu artigo 4웅 estabelece como dever do Estado com a educação escolar pública a garantia de oferta de atendimento escolar especializado gratuito para estudantes com deficiência, transtornos globais do desenvolvimento e altas habilidades ou superdotação, transversal a todos os níveis, etapas e modalidades, preferencialmente na rede regular de ensino (BRASIL, 1996).

Na próxima seção, trataremos sobre os desafios que o distanciamento social, com suspensão das aulas presenciais devido à pandemia da Covid-19, gera para as o processo de ensino e aprendizagem inicial da leitura por crianças com ou sem distúrbios nessa aprendizagem.

3 Desafios para a aprendizagem da leitura decorrentes do ensino remoto

A Covid-19 impulsionou as pessoas a reverem formas de vida, de interação, de trabalho e também de educação, gerando um cenário inédito. Nas escolas, um clima de incertezas passou a pairar, ao mesmo tempo em que soluções deveriam ser buscadas num curtíssimo período de tempo. A comunidade escolar dividiu-se entre a retomada das atividades e a espera pela vacina para maior garantia de segurança sanitária na aproximação entre docentes e discentes.

Se o processo de desenvolvimento da leitura antes da pandemia já trazia questionamentos e discussões diversas aos professores, enquanto isolados em suas casas devido à pandemia, estes tentam de alguma forma alcançar seus estudantes e perceber, por meio do ambiente virtual, suas dificuldades, ansiedades e desejos, buscando ainda mais conhecimentos que possibilitem a qualidade do ensino e da aprendizagem. Os docentes têm se empenhado para que o maior número de estudantes seja alcançado pela proposta de ensino e que estes alcancem um desempenho satisfatório. Uma das maiores preocupações de professores e da comunidade escolar como um todo consiste em saber se os alunos estão realmente aprendendo e, no caso das crianças em estágio inicial de aprendizagem de leitura, esta preocupação é ainda maior, pois seu processo de aprendizagem na modalidade presencial estava apenas começando quando a pandemia surgiu.

Entre os professores o desafio do ensino remoto - diferente da educação a distância - começou pelo acesso às ferramentas necessárias para a comunicação pelo meio virtual. Falamos de 
professores que não estavam acostumados a utilizar ferramentas digitais no dia a dia e não estavam familiarizados com as práticas específicas necessárias para esta modalidade de ensino, ou ainda, que não possuíam a tecnologia necessária em termos de computador ou laptop adequado ou uma internet de qualidade.

Por sua vez, as famílias tiveram sua dinâmica de organização modificada bruscamente, e muitas delas, em situação de vulnerabilidade social, não tiveram condições de oferecer um ambiente adequado para a continuidade das atividades educativas das crianças em meio virtual. Somou-se a isso a falta de ferramentas tecnológicas (computador, celular, tablet), de internet, e ainda de conhecimentos suficientes dos pais ou responsáveis para que as atividades encaminhadas pelos educadores fossem realizadas conforme o solicitado. Ou ainda, em famílias mais numerosas, a disputa pelos equipamentos se tornou um obstáculo, ainda mais em atividades síncronas de pais e filhos. Outra grande dificuldade ocorreu nos casos em que os pais continuaram suas atividades profissionais e tiveram de resolver a questão de os filhos não serem atendidos em suas escolas.

Devemos observar também a posição dos estudantes que, estando em suas casas, não estavam acostumados a manter a rotina de estudos, participar de atividades virtuais com postura estudantil. As distrações do conforto ou da familiaridade que o lar oferece podem facilmente obstruir o processo de aprendizagem. A própria necessidade de manterem-se isolados, distantes dos colegas, pode gerar situações de ansiedade e insegurança. Sabemos o quanto a saúde emocional tem influência sobre os processos de aprendizagem. Cosenza e Guerra (2011, p. 130) explicam que o ambiente ao qual estamos expostos influencia o processo de aprendizagem, interferindo nos fatores psicológicos e emocionais e induzindo a comportamentos que podem ser mais ou menos favoráveis ao aprendizado. Seguindo este raciocínio, Ferreira (2014, p. 17) explica que tudo o que vivemos sempre está influenciado por matiz emocional. Cosenza e Guerra (2011) acrescentam que
- cérebro da criança estará processando os estímulos gerados por essas mudanças de forma a produzir um comportamento que permita a melhor adaptação às situações vividas. Assim, os circuitos neuronais que deveriam estar envolvidos nas tarefas escolares estarão ocupados com comportamentos, que, naquele momento, são mais relevantes para a sobrevivência e 0 bem-estar. (COSENZA; GUERRA, 2011, p. 131)

Conforme tratamos no início deste artigo, há habilidades que precisam ser ensinadas, sendo a leitura umas delas. Crianças são acostumadas a aprender a partir do diálogo, da troca de informações e da presença física, do brincar e da experimentação. Pequenos aprendizes em estágio inicial do desenvolvimento da leitura estão aprimorando suas habilidades cognitivas e construindo a capacidade de abstração. Crianças que apresentam dificuldades de aprendizagem, não só de leitura, ou capacidade de atenção reduzida, podem ter ainda mais problemas para entender a proposta de ensino, devido a interferências emocionais e comunicativas no ambiente em que se encontram.

A aprendizagem e o desenvolvimento da habilidade leitora dependem de uma continuidade de ações. Como é entendida como um processo, a sequência de atividades é importante para que a construção cognitiva da criança seja contínua. De maneira prática, entendemos que

O alvo do ensino da leitura é, pois,
claro: é preciso colocar essa hierarquia
no cérebro, a fim de que a criança
possa reconhecer as letras e os
grafemas e os transformar facilmente
em imagens acústicas de sua língua.
Todos os outros aspectos do sistema
escrito - a aprendizagem da ortografia,
o enriquecimento do vocabulário, as
nuances do sentido, o prazer do estilo-
dependem disso diretamente.
(DEHAENE, 2012, p. 236)

Para que a criança tenha acesso a uma aprendizagem contínua é preciso a união de empenhos. Um dos questionamentos mais recorrentes sobre o período de alfabetização é a respeito da relação entre a família e a escola durante este processo. A disparidade entre ambientes familiares quanto ao nível socioeconômico e à escolaridade dos pais implica a qualidade e quantidade dos estímulos 
dispensados às crianças aprendizes. Morais (2019, p. 3) salienta que pobreza e riqueza, aplicadas quer à linguagem, quer à posse de bens materiais, são os polos extremos de uma variável contínua. É inegável o quanto o nível de bem-estar social, de entretenimento qualificado, de exposição à leitura e à escrita, da escolaridade dos pais, interagem com a competência na leitura das crianças e jovens, fatores estes bastante atrelados aos socioeconômicos (SOUSA; HUBNER, 2017).

Acreditamos que um ponto crucial a ser observado para conduzir a aprendizagem de leitura (e o ensino em geral) em tempos de pandemia é oferecer às crianças menos favorecidas uma atenção especial em um momento em que as diferenças se mostram ainda mais proeminentes. Do contrário, as diferenças na qualidade da aprendizagem que já foram evidenciadas nos resultados das avaliações de nível internacional tendem a ser novamente evidenciadas no Brasil e, possivelmente, de forma ainda mais acentuada no período pós-pandemia.

Considerando especificamente os aprendizes com transtornos de aprendizagem de leitura, urge um modelo escolar mais inclusivo e abrangente. A escola precisa oferecer melhores condições em termos de equipamentos e materiais, assim como os professores devem ter melhor preparo e formação específica para práticas direcionadas àqueles estudantes que precisam de maior atenção especializada. $O$ conhecimento sobre como auxiliar os aprendizes no início da aprendizagem da leitura e ao longo dos anos escolares, em especial aqueles com dificuldades ou transtornos, deveria ser requisito dos profissionais que trabalham na promoção de tal aprendizagem, a fim de que as limitações encontradas pelo caminho pudessem ser superadas.

Ensinar a ler em tempos de pandemia configura-se como um novo desafio. Esta é uma provocação para que educadores e pesquisadores possam aplicar ferramentas ainda mais inovadoras partindo dos resultados de estudos recentes, os quais têm demonstrando que a mente humana expande suas capacidades e habilidades quando estimulada e desafiada de forma adequada. Ao mesmo tempo, habilidades de autonomia, organização e responsabilidade para com sua aprendizagem devem ser estimuladas nos estudantes desde bem pequenos.

Deparamo-nos, em meio à pandemia, com muitas limitações, especialmente na oferta de materiais adaptados para estudantes com deficiências diversas, como no caso de transtornos para a aprendizagem de leitura, ou nas limitações de ordem cognitiva, visual, auditiva, entre outras. Este cenário nos mostrou a urgência de desenvolvermos materiais adaptados e adequados para as peculiaridades dos estudantes, fato que se percebe na grande quantidade de material didático digital que vem sendo criado e disponibilizado nas redes sociais e plataformas de ensino. Importante, no entanto, é que este material chegue a quem deve chegar.

\section{Considerações Finais}

Discutimos aqui os processos envolvidos na aprendizagem inicial da leitura, incluindo casos de dificuldades e de transtornos de leitura, associados aos desafios impostos pela pandemia da Covid-19 ao contexto social e educacional.

Quando trabalhamos com educação, em função da multiplicidade cultural e das diferenças pessoais, não existem receitas de como tornar o ensino eficaz. Conhecer os processos que fazem parte do desenvolvimento da habilidade de leitura e entender como funciona a cognição humana podem ser formas de buscar alternativas para a nova realidade. Independente de termos estudantes com ou sem dificuldades de leitura sob nossa responsabilidade, o olhar preciso e a resposta rápida aos desdobramentos da aprendizagem podem fazer muita diferença no resultado que se busca.

Podemos observar que este novo modelo de ensino (remoto emergencial) não consegue garantir o acesso universal à escola. A desigualdade social e cultural neste país tão vasto impõe a necessidade de encontrarmos modos específicos e especiais de ensino a partir de cada realidade local. A pandemia escancarou, de forma contundente e inesperada, o que 
já sabíamos mas não enfrentávamos: o fato de que precisamos evoluir no âmbito do ensino e aplicar conhecimentos multidisciplinares, incluindo evidências das neurociências, para tornar os processos educacionais mais efetivos e integrados. Quiçá as forças que nos desacomodaram por conta da pandemia possam nos impulsionar a uma nova realidade, à tomada de medidas para uma realidade educacional mais atualizada, eficiente e igualitária.

\section{Referências}

ALTREIDER, Asta. Dislexia: varlendo contra o vento. In: ROTTA, N. T.; BRIDI FILHO, C. A.; BRIDI, F. R. de S. (Orgs.) Neurologia e aprendizagem: abordagem multidisciplinar. Porto Alegre: Artmed, 2016. 327 p.

BRASIL. Ministério de Educação e Cultura. LDB - Lei no 9394/96, de 20 de dezembro de 1996. Estabelece as diretrizes e bases da Educação Nacional. Brasília: MEC, 1996.

BUITELAAR, J. K., VAN DER MEER, D., RICHARDS, J. Compreendendo os fundamentos da neurobiologia do TDAH. In: ROHDE, L.A. et al. (Orgs.) Guia para a compreensão e manejo do TDAH da World Federation of ADHD. Porto Alegre: Artmed, 2019.

COLTHEART, Michael. Modeling Reading: The Dual-Route Approach. In: The Science of Reading: A Handbook. SNOWLING, Margaret J. and HULME, Charles (Ed.). Oxford: Blackwell Publishing Ltd, 2005. $661 \mathrm{p}$

COSENZA, Ramon M., GUERRA, Leonor B. Neurociência e educação: como o cérebro aprende. Porto Alegre: Artmed, 2011. 150 p.

DEHAENE, Stanislas. Os neurônios da leitura. Porto Alegre: Penso, 2012. 374 p.

FERREIRA, Maria G. R. Neuropsicologia e aprendizagem. Curitiba: InterSaberes, 2014. 241 p.

FONSECA, Vitor da. Cognição, neuropsicologia e aprendizagem: abordagem neuropsicológica e psicopedagógica. Petrópolis: Vozes. 2011. 183 p.

IBGE. Séries históricas e estatística. Disponível em:

https://seriesestatisticas.ibge.gov.br/series.aspx?no=4
$\& o p=0 \& v$ codigo $=E C E 370 \& t=$ media-anos-estudopessoas-10-anos\# acessado em 14 de julho de 2020.

LEAL, Daniela, NOGUEIRA, Makeliny O. G. Dificuldades de aprendizagem: um olhar psicopedagógico. Curitiba: InterSaberes, 2012.170 p.

LENT, Roberto. O cérebro aprendiz: neuroplasticidade e educação. São Paulo: Atheneu, 2018. 148 p.

MORAIS, José. A arte de ler. São Paulo: Editora da Universidade Estadual Paulista, 1996. 317 p.

MORAIS, José. Criar leitores: para professores e educadores. Barueri: Minha Editora, 2013. 154 p.

MORAIS, José. O que faz a diferença entre a linguagem rica e a linguagem pobre? Signo. Santa Cruz do Sul, v.44,n. 81, p. 02-21, set./dez. 2019.

NUNES, Terezinha, BUARQUE, Lair, BRYANT, Peter. Dificuldades na aprendizagem da leitura. Teoria e prática. São Paulo: Cortez: 1992. 111 p.

OECD. Brazil - Country Note - PISA 2018 Results. Disponível em: https://www.oecd.org/pisa/publications/PISA2018_CN BRA.pdf acessado em 14.07.2020.

RELVAS, Marta P. Neurociência e transtorno de aprendizagem: as múltiplas eficiências para uma educação inclusiva. 6 ed. Rio de Janeiro: Wak Editora, 2015. 144p.

RIESGO, Rudimar dos S. Anatomia da aprendizagem. In: Rotta, Newra T., Ohlweiler, Lygia, Riesgo, Rudimar dos S. (Orgs.) Transtornos da Aprendizagem: abordagem neurobiológica e multidisciplinar. 2 ed. Porto Alegre: Artmed, 2016. 496 p.

ROTTA, Newra T. Plasticidade cerebral e aprendizagem. In: Rotta, Newra T., Ohlweiler, Lygia, Riesgo, Rudimar dos S. (Orgs.) Transtornos da Aprendizagem: abordagem neurobiológica e multidisciplinar. 2 ed. Porto Alegre: Artmed, 2016. 496 p.

ROTTA, Newra T. Dificuldades para aprendizagem. In: Rotta, Newra T., Ohlweiler, Lygia, Riesgo, Rudimar dos S. (Orgs.) Transtornos da Aprendizagem: abordagem neurobiológica e multidisciplinar. 2 ed. Porto Alegre: Artmed, 2016. 496 p. 
SOUSA, Lucilene Bender; HÜBNER, Lilian Cristine. A relação entre desempenho em compreensão leitora e fatores socioeconômicos. Fórum Linguístico, v. 14, no. 2, 2017. https://doi.org/10.5007/1984-8412.2017v14n2p2044

TEIXEIRA, Mariana T., TOWNSEND, Sabrine A. M. O que a literacia e as capacidades cognitivas do cérebro podem nos dizer sobre pensamento crítico? Revista da Abralin, v. 19, n. 2, p. 1-6, 2020.

VAN KLEECK, Anne; NORLANDER, Elizabeth. Fostering Form and Meaning in Emerging Literacy Using Evidence-Based Practice. In: MODY, Maria and SILLIMAN, Elaine R. (ed.) Brain, Behavior, and Learning in Language and Reading Disorders. New York: The Guilford Press, 2008. 400 p.
PACHECO, Letícia Priscila; HÜBNER, Lilian Cristine. Como o distanciamento social em tempos de pandemia desafia os estágios iniciais da aprendizagem da leitura em crianças. Signo, Santa Cruz do Sul, v. 46, n. 85, p. 58-69, jan. 2021. ISSN 1982-2014. Disponível em: $<$ https://online.unisc.br/seer/index.php/signo/article/vie w/15672>.

doi:https://doi.org/10.17058/signo.v46i85.15672. 